\title{
ANALISIS SWOT TERHADAP \\ PENGELOLAAN UNIT KEGIATAN MAHASISWA \\ MANNA PROXIA THEATER \\ UNIVERSITAS PELITA HARAPAN
}

\author{
Elia Yovan Chandra \\ eliayovan@gmail.com
}

\begin{abstract}
Abstrak
Manna Proxia Theater (MPT) adalah sebuah Unit Kegiatan Mahasiswa (UKM) di Universitas Pelita Harapan (UPH) yang bergelut di bidang seni peran. Keunikan pengelolaan MPT adalah karena ia lahir di bawah pengelolaan pendidikan yang memiliki kontrol ketat khas Universitas Pelita Harapan, namun pada perkembangannya juga dikelola bersama dengan mahasiswa melalui Badan Pengurus Harian (BPH-MPT). Pada saat ini, MPT menghadapi berbagai tantangan seperti minimnya fasilitas, regulasi yang memberatkan, dan dukungan dana yang kurang. Bagaimanapun, terdapat pula peluang pengembangan MPT seiring tumbuhnya industri kreatif serta teknologi di Jakarta. Untuk itu, MPT perlu memiliki strategi pengelolaan yang dapat mengakomodasi sumber daya yang dimilikinya terus berkembang sebagai sebuah UKM. Analisa SWOT diaplikasikan untuk mengidentifikasi dan menganalisa eksistensi MPT saat ini dan bagaimana MPT dapat terus mempertahankan produktifitasnya tanpa kehilangan orientasinya. Penelitian dilakukan dengan mewawancarai beberapa pihak kunci (key person) di MPT dan memformulasikan hasilnya dalam sajian Matriks IE, Kuadran SWOT, dan Matriks SWOT. Hasilnya, ditemukan bahwa kondisi MPT saat ini berada dalam posisi potensial untuk tumbuh dan melakukan perluasan pasar. Oleh karena itu, diperlukan berbagai strategi seperti memperluas pasar, mengembangkan produk baru, membangun integrasi dengan berbagai pihak, dan selalu menghadirkan karya yang unik dan menarik perhatian mahasiswa UPH.
\end{abstract}

Kata kunci : pengelolaan seni pertunjukan, unit kegiatan mahasiswa, teater, swot

\section{Pendahuluan}

Penelitian tentang Unit Kegiatan Mahasiswa (UKM) dalam kaitannya dengan dunia tata kelola seni adalah hal yang masih jarang dilakukan. Padahal, UKM dapat dikatakan sebagai merupakan salah satu wadah penggodokan calon seniman, karena tidak sedikit seniman yang talenta seninya diasah dari sini (Park, 2015). Dengan demikian, di dalam konteks seni pertunjukan, penelitian terhadap UKM dapat memberikan wawasan baru dan berharga bagi pengembangan seni pertunjukan, khususnya di Indonesia.

Manna Proxia Theatre (MPT) adalah sebuah UKM di Universitas Pelita Harapan yang berdiri pada bulan Mei 2008. Sebagai sebuah UKM, natur dari MPT sejatinya adalah educational-driven atau berorientasi pada pendidikan. Artinya, pergerakan MPT berpusat pada upayanya untuk menyediakan wadah belajar/pendidikan bagi para anggotanya. Meskipun kuantitas pertunjukan bukanlah tujuan utama dari MPT, namun ternyata MPT menunjukkan 
produktifitas yang cukup baik dengan belasan pertunjukan yang sudah dilangsungkannya, baik di dalam maupun di luar ruang lingkup UPH.

Kehadiran MPT di UPH tergolong unik. UPH dikenal sebagai universitas yang memiliki kontrol tatakelola yang sangat ketat, bahkan cenderung kaku. Pada awal pendiriannya, MPT yang disebut UKM ini bahkan tidak memiliki badan pengurus yang berasal dari mahasiswa. Dengan kata lain, mulai dari pengurus hingga instruktur semuanya diangkat dan dikontrak oleh bagian Human Resources and Development Yayasan Pendidikan Pelita Harapan (HRD). Mahasiswa hanya sebagai anggota dengan kontrol yang sangat minim terhadap program, instruktur, dan kelembagaan. Sejak satu tahun terakhir, telah terjadi perubahan di dalam tubuh MPT. Dari yang sebelumnya tertutup dengan interfensi mahasiswa, kini telah memiliki BPHnya sendiri. Hal ini tentu memberikan warna dan gaya pengelolaan yang baru di MPT.

Di tengah proses adaptasi dan upaya sinergi antara BPH dan instruktur yang ada, MPT juga menghadapi lingkungan yang baru. Tren industri kreatif dalam bentuk seni pertunjukan dan perfilman yang mulai menggeliat sedikit banyak berpengaruh terhadap minat pasar MPT. Teater yang dahulunya identik dengan kumpulan mahasiswa urakan dan aneh kini mulai dipandang salah satu jalan masuk dalam karier seseorang di industri kreatif. Hal ini turut memengaruhi keseluruhan hidup MPT itu sendiri; karena segmen peminatnya yang perlahan berubah, pola didik, materi, dan konten promosipun turut berubah. Di sisi lain, tantangan yang dihadapi MPT ternyata tidak berubah terlalu drastis. Masalah klasik seperti buruknya fasilitas pendukung (mic, properti, gedung pertunjukan, dll), penurunan kualitas akting anggota, dan hingga rendahnya peminat terhadap materi yang berat menjadi tantangan yang harus segera ditemukan solusinya.

Hal ini kemudian menghasilkan kesadaran perlunya dilakukan kajian terhadap kondisi yang tengah dan akan dijalani oleh MPT kedepannya dan bagaimana strategi yang tepat untuk menjadikan MPT tetap kompetitif dan mampu bertahan sebagai salah satu UKM unggulan di UPH. Atas dasar itulah, menurut hemat peneliti penting untuk dilakukan penelitan mengenai strategi kompetitif yang perlu dilakukan oleh MPT. Adapun model analisis yang digunakan adalah dengan menggunakan SWOT Termodifikasi. SWOT Termodifikasi pada dasarnya adalah model analisa yang dimaksudkan untuk memahami MPT secara luar dalam dan merumuskan strategi yang tepat untuk dilakukan berdasarkan kelebihan dan kekurangan MPT, serta peluang dan ancaman yang akan dihadapi mereka kedepannya. Dengan melibatkan para pengambil keputusan di MPT, diharapkan hasilnya dapat menjadi studi awal yang komperhensif bagi perumusan strategi kompetitif MPT berikutnya.

\section{Manajemen Strategis}

Menurut Wells (1996, hlm. 3), manajemen strategis adalah sebuah pendekatan sistem untuk mengidentifikasi dan membuat perubahan yang diperlukan serta mengukur kinerja organisasi dalam konteks pencapaian visi organisasi tersebut. Manajemen strategis juga dapat didefenisikan sebagai sistem manajemen yang mengaitkan perencanaan strategis dengan pengambilan keputusan dalam konteks pengelolaan operasional hariannya (Gluck, Kaufman, dan Walleck, 1982 dalam Wells, 1996). Meski demikian, sebuah manajemen strategis lebih merupakan proses yang berkesinambungan daripada proses yang hanya dilakukan sekali saja. 
Sementara itu menurut David (2011, hlm. 6), manajemen strategis dapat diartikan sebagai seni dan ilmu dalam memformulasi, mengimplementasi, dan mengevaluasi keputusankeputusan sebuah organisasi untuk mencapai tujuan-tujuannya. Secara praktis, hal ini berarti manajemen strategis akan berfokus pada pengintegrasian pengelolaan, pemasaran, finansial, produksi/operasi, penelitian, hingga sistem informasi sebuah organisasi untuk mencapai tujuan mereka (David, 2011).

\section{Analisis SWOT}

SWOT (strengths, weaknesses, opportunities, threads) adalah salah satu analisis paling banyak digunakan di seluruh dunia dalam pembentukan manajemen strategi pada sebuah organisasi yang semuanya merupakan faktor-faktor strategis bagi perkembangan organisasi tersebut (David, 2011). Menurut Rangkuti (2004), analisis SWOT adalah identifikasi berbagai faktor secara sistematis untuk merumuskan strategi perusahaan. Analisis ini didasarkan pada logika yang dapat memaksimalkan kekuatan (strength) dan peluang (opportunity), namun secara bersamaan dapat meminimalkan kelemahan (weaknesses) dan ancaman (threats).

Cara kerjanya adalah dengan mengumpulkan informasi dari analisa lingkungan dan perusahaan yang dilakukan, kemudian memisahkannya ke dalam faktor internal (kekuatan dan kelemahan) dan faktor eksternal (peluang dan ancaman). Setelah selesai, kemudian akan dihasilkan berbagai strategi bagi perusahaan untuk mencapai tujuan mereka, hambatan yang harus diatasi atau diminimalisir untuk mencapai hasil yang diharapkan (Singh, 2010 dalam Ommani, 2011). Dengan demikian, perencanaan strategi harus mampu menganalisa berbagai faktor tersebut secara akurat dan aktual.

SWOT dapat dibagi ke dalam dua kategori faktor: internal dan eksternal. Faktor internal memengaruhi terbentuknya kekuatan dan kelemahan di mana faktor ini berkaitan dengan kondisi yang terjadi dalam perusahaan. Sementara faktor eksternal mempengaruhi terbentuknya peluang dan ancaman, dimana faktor ini berhubungan erat dengan kondisikondisi yang terjadi di luar perusahaan yang mempengaruhi dalam pembuatan keputusan perusahaan (Fahmi, 2013 dalam Nisak, 2014). Berbeda dengan faktor internal, faktor eksternal adalah hal-hal yang diprediksi akan terjadi dalam waktu dekat, namun belum terjadi (David, 2011).

\section{Model Analisis SWOT}

Model SWOT yang digunakan dalam penelitian ini adalah Strategy-Formulation Analytical Framework (David, 2011) yang terbagi dalam tiga tahap utama, yaitu Tahap masukan (Input stage), Tahap pencocokan (Matching Stage), dan terakhir Tahap keputusan (Decision stage).

\section{Tahap Masukan}

Pada tahap ini dilakukan analisis internal untuk mengetahui kekuatan dan kelemahan yang dimiliki oleh perusahaan. Analisis ini disajikan dalam matriks Internal Factor Evaluation (IFE) dan External Factor Evaluation (EFE). Adapun langkah-langkah dalam penyusunan matiks EFE dan IFE adalah: (1) Identifikasi Faktor Internal dan Eksternal Perusahaan, (2) 
Pemberian Bobot Faktor, (3) Pemberian Rating (Peringkat), dan (4) Perkalian Bobot dan Peringkat.

\section{Tahap Pencocokan}

Tahap pencocokan merupakan tahap untuk mencocokan peluang dan ancaman eksternal dengan kekuatan dan kelemahan internal berdasarkan informasi yang didapatkan pada tahap masukan. Alat analisis yang digunakan dalam penelitian ini untuk tahap pencocokan adalah matriks IE (Internal-External), kuadran SWOT, dan matriks SWOT.

\section{Tahap Keputusan}

Pada tahap ini, pengambilan keputusan dilakukan dengan menggunakan hasil strategistrategi yang diperoleh dari tahap sebelumnya, yaitu tahap masukan dan pencocokan.

\section{Metode Penelitian}

Penelitian ini dilakukan terhadap MPT sebagai objek penelitian pada tanggal 26 November sampai 30 November 2015 bertempat di Kantor ART Division, UPH Lippo Village, Tangerang. Sebagai subyek penelitannya adalah para key person yang ketiganya merupakan pengambil keputusan untuk MPT. Mereka adalah Novel Priyatna (Student Life Director) yang berperan sebagai penjembatan antara ART Division dan UPH, Boy Marpaung (ART Division Manager) yang memegang posisi tertinggi di ART Division, dan Fransiskus Asisi (Program Specialist) sebagai Program Specialist yang mengatur berbagai program dan target-target rinci untuk dikerjakan oleh instruktur MPT.

Pendekatan kualitatif dilakukan dengan mewawancarai ketiganya untuk mengumpulkan pendapat mengenai faktor internal dan eksternal yang memengaruhi MPT saat ini. Selain itu, bagian Humas BPH MPT juga diwawancarai untuk mendapatkan dan mengkonfirmasi keabsahan berbagai data sekunder yang diperoleh dari media elektronik maupun cetak.

Beserta observasi peneliti, hasil wawancara mengenai kekuatan, kelemahan, peluang, dan ancaman MPT tersebut dituangkan ke dalam bentuk matriks IFE, matriks EFE, dan Matriks Profil Kompetitif. Keseluruhan proses ini termasuk di dalam tahap masukan. Selanjutnya, dalam tahap pencocokan, matriks IFE dan EFE diformat ke dalam bentuk kuesioner kepada key person untuk diberi bobot dan peringkat. Proses ini menggunakan pendekatan kuantitatif di mana hasilnya nanti yang berupa angka akan dikuantifikasi, dan dicocokkan ke dalam bentuk matriks IF, kuadran SWOT, dan matriks SWOT. Langkah terakhir adalah tahap keputusan berupa rumusan langkah-langkah strategis yang dapat dilakukan MPT berdasarkan hasil yang telah dilakukan pada tahap sebelumnya.

\section{Temuan dan Pembahasan}

Hasil dari pengumpulan data kualitatif dan kuantitatif menghasilkan temuan-temuan yang mengacu pada Strategy-Formulation Analytical Framework dapat digolongkan ke dalam tahap masukan (input stage) dan pencocokan (matching stage). 
Tahap Masukan (Input stage)

\section{Lingkungan Umum}

Lingkungan umum dapat diartikan sebagai lingkungan eksternal yang memiliki kaitan dengan perkembangan MPT.

\section{Gaya Hidup (Lifestyle)}

Faktor pertama adalah mengenai gaya gidup. Gaya hidup mahasiswa yang masih mendominasi saat ini terkesan masih kurang ramah terhadap kesenian, khususnya kesenian yang membutuhkan gengsi sangat rendah seperti teater. Hal ini menjadi salah satu penghalang dari tingginya animo mahasiswa untuk terlibat di MPT.

\section{Politik Kampus}

Kuatnya kontrol UPH terhadap MPT di satu sisi memberikan kepastian dukungan yang tinggi dari universitas. Sayangnya, kontrol yang kuat juga berdampak pada berbagai benturan antara kreativitas pelaku seni dengan batasan religius kampus sehingga terkesan mempersempit ruang gerak kreativitas pimpinan dan anggota MPT untuk berkreasi.

\section{Teknologi}

Perkembangan teknologi dewasa ini terang-terangan mengubah cara bersantai dan berekspresi kebanyakan generasi muda, termasuk di dunia seni pertunjukan, di mana panggung dalam wujud nyata disaingi oleh panggung digital dalam bentuk klip, video, dan film-film yang dapat dengan mudah diproduksi oleh generasi sekarang. Hal ini juga menjadi dinamika tersendiri bagi MPT, dimana para anggotanya berpeluang untuk menambah panggung eksistensi mereka, dari hanya pertunjukan live kepada pertunjukan digital yang memiliki daya jangkau lebih luas dan cepat. 


\section{Matriks Profil Kompetitif (Porter's Five Forces Framework)}

Selain lingkungan umum, data yang terkumpul juga dapat memberikan gambaran mengenai posisi kompetitif MPT di antara UKM lain di UPH, seperti yang dirangkum dalam tabel berikut:

\begin{tabular}{|c|c|}
\hline $\begin{array}{l}\text { Rivalry among competing } \\
\text { firms } \\
\text { Persaingan: antar-UKM } \\
\text { Posisi MPT: } 8 / 10\end{array}$ & $\begin{array}{l}\text { MPT termasuk salah satu UKM yang berdiri paling awal } \\
\text { di UPH. Dengan berbagai gebrakan yang dilakukannya } \\
\text { selama ini, MPT telah memiliki nama besar dan dikenal } \\
\text { luas oleh mahasiswa. Sejak awal berdiri, MPT selalu } \\
\text { memiliki pasarnya sendiri. Peminatnya cukup tinggi } \\
\text { sampai hari ini dan memiliki angka pertumbuhan } \\
\text { anggota yang stabil. Dapat dikatakan MPT memimpin } \\
\text { posisi UKM di UPH dengan beberapa kali memeroleh } \\
\text { penghargaan sebagai Student Activity Unit of the year di } \\
\text { UPH Awards. }\end{array}$ \\
\hline $\begin{array}{l}\text { Potential development of } \\
\text { substitute products } \\
\text { Produk pengganti : Movie } \\
\text { Production Club (MPC). } \\
\text { Posisi MPT : } 7 / 10\end{array}$ & $\begin{array}{l}\text { Kehadiran MPC dapat menarik perhatian mahasiswa } \\
\text { yang tertarik dengan dunia seni peran yang lebih modern } \\
\text { dan berpotensi menyedot animo mahasiswa, baik yang } \\
\text { belum tergabung di UKM maupun anggota MPT. } \\
\text { Sejauh ini, MPT berusaha meresponi hal ini dengan } \\
\text { membuat banyak kerjasama dengan MPC dari } \\
\text { meminjamkan talent maupun proyek kolaborasi. } \\
\text { Tujuannya adalah untuk meyakinkan mahasiswa bahwa } \\
\text { tergabung dengan MPT tidak menutup pintu mereka } \\
\text { untuk mencoba hal-hal baru. }\end{array}$ \\
\hline $\begin{array}{l}\begin{array}{l}\text { Potential entry of new } \\
\text { competitor }\end{array} \\
\text { Kompetitor baru : - } \\
\text { Posisi MPT : } 9.5 / 10\end{array}$ & $\begin{array}{l}\text { Sesuai dengan keinginan UPH yang membuka UKM } \\
\text { sebagai sarana berkomunitas dan belajar - bukan } \\
\text { berkompetisi, maka implikasinya adalah hanya boleh } \\
\text { ada satu UKM per bidang seni di bawah naungan } A R T \\
\text { Division. Ini menjadi hambatan besar bagi (seaindainya } \\
\text { ada) mahasiswa yang ingin membuat klub teaternya } \\
\text { sendiri. Dengan kata lain, hanya satu dan akan selalu } \\
\text { satu UKM teater di UPH, yaitu MPT. }\end{array}$ \\
\hline $\begin{array}{l}\text { Bargaining power of supplier } \\
\text { Supplier : } \\
\text { Fakultas/Jurusan Posisi : } 6 / 10\end{array}$ & $\begin{array}{l}\text { Keberadaan MPT sebagai kegiatan sampingan akademis } \\
\text { sejatinya menyebabkan daya tawarnya terhadap } \\
\text { Fakultas dan Jurusan cukup lemah. Meski begitu, MPT } \\
\text { tengah menjalin komunikasi dan terlibat dalam berbagai } \\
\text { kegiatan fakultas agar dapat terjadi sinergi yang } \\
\text { menguntungkan bagi keduanya. }\end{array}$ \\
\hline $\begin{array}{l}\begin{array}{l}\text { Bargaining powers of } \\
\text { consumers }\end{array} \\
\text { Consumer : anggota } \\
\text { MPT \& mahasiswa UPH Posisi } \\
: 7 / 10\end{array}$ & $\begin{array}{l}\text { UKM dikenal sebagai penghasil seniman-seniman } \\
\text { muda. Fenomena ini ditangkap dengan baik oleh MPT } \\
\text { dengan menjaga ikatan dan komitmen anggota lewat } \\
\text { media komunikasi dan yang dibentuk selama ini terbukti } \\
\text { efektif untuk menjaga konsistensi berlatih dan } \\
\text { keterlibatan mahasiswa. Selain itu, MPT juga membuka } \\
\text { jam-jam lembur untuk mahasiswa yang baru dapat } \\
\text { mulai datang di sore/malam hari. Meski demikian, di sisi } \\
\text { lain program dan disiplin yang dilakukan perlu } \\
\text { dipikirkan baik-baik pula agar tiap tahunnya angka } \\
\text { pertumbuhan anggota MPT terus memuaskan. }\end{array}$ \\
\hline
\end{tabular}




\section{Peluang dan Ancaman (Matriks EFE)}

Berdasarkan analisa situasi lingkungan umum dan profil kompetitif yang dilakukan di atas, maka dirumuskan beberapa faktor eksternal yang akan memengaruhi perkembangan MPT ke depannya. Berikut ini adalah faktor tersebut beserta penjelasannya :

\section{Peluang}

1. Apresiasi pasar yang bisa lebih baik terhadap pertunjukan teater. Tiga tahun belakangan ini, para key person mengamati terjadinya peningkatan animo penikmat seni, termasuk teater, dari kalangan yang lebih muda (eksekutif muda, kaum produktif). Jika memang tren ini terus berlanjut, maka demam menonton teater tidak lama lagi diprediksi akan turut melanda mahasiswa UPH dan menghadirkan lahan potensial untuk digarap.

2. Saat ini semakin banyak rumah produksi yang mencari talenta dari kampus. Hal ini mendorong banyak rumah produksi mencari talenta yang tidak hanya berpenampilan menarik namun memiliki kemampuan akting yang mumpuni. Setelah beberapa anggota MPT berhasil menembus FTV dan film layar lebar, para key person percaya kedepannya UPH akan didatangi lebih banyak rumah produksi lagi untuk mencari talenta-talenta akting muda yang segar.

3. Masih terkait dengan talenta akting, UKM Movie Production Club-pun tak ketinggalan diprediksi masuk dalam perburuan aktor dan aktris untuk film mereka. Seiring semakin berkembangnya kualitas dan kuantitas karya mereka, maka peluang datangnya tawaran bermain dari mereka di tahun depan akan semakin terbuka.

4. Setelah terbentuknya BPH, Program Specialist dan Manager ART Division jadi memiliki waktu lebih banyak untuk membangun kemitraan dengan banyak korporasi. Kedepannya diprediksi, bahwa akan ada lebih banyak kerjasama yang terbangun antara MPT dengan berbagai korporasi.

\section{Ancaman}

5. Dengan semakin banyaknya jumlah mahasiswa yang masuk UPH setiap tahunnya, maka UKM yang tersedia tidak akan lagi dapat menampung seluruh minat dan jumlah mahasiswa. Kedepannya diprediksi akan banyak UKM-UKM baru yang dibuka, seni maupun non-seni yang berpotensi mengambil pasar yang telah menjadi milik MPT sebelumnya.

6. Penerapan intervensi penuh HRD terhadap perekrutan pada TA 2016/17 bisa menjadi penghambat pertumbuhan MPT. Dengan sistem perekrutan HRD yang ketat dan rumit, maka kemungkinan mendapat pelatih tambahan berkualitas menjadi semakin tertutup.

7. Rencana efisiensi anggaran sebanyak 5\% pada TA 2016/17 menjadi ancaman tersendiri bagi berbagai pertunjukan yang telah direncanakan MPT. Untuk itu, perlu disusun langkah strategis untuk menipiskan persentasi pemotongan menjadi 1-2\% saja atau mencari sumber dana dari tempat lain.

8. Salah satu ketakutan MPT adalah ketika posisi pengambil keputusan yang berhubungan dengan MPT tidak dihuni oleh orang yang memahami seni di periode berikutnya karena berpengaruh langsung terhadap kelangsungan hidup MPT. 
Kedelapan faktor tersebut dirangkum dalam bentuk Matriks Evaluasi Faktor Eksternal. Matriks ini bertujuan untuk menggambarkan dengan lebih akurat faktor eksternal yang ada melalui pemberian bobot dan skor pada setiap indikator. Setiap indikator telah diverifikasi oleh tiga key persons dalam pengurusan MPT, kemudian dibobot dan diskor oleh mereka.

\begin{tabular}{|c|c|c|c|}
\hline Faktor Internal Kunci & Bobot & Peringkat & $\begin{array}{l}\text { Nilai } \\
\text { tertimbang }\end{array}$ \\
\hline \multicolumn{4}{|l|}{ Peluang } \\
\hline $\begin{array}{l}\text { Apresiasi pasar yang bisa LEBIH BAIK } \\
1 \text { terhadap pertunjukan teater }\end{array}$ & 0.12 & 3.3 & 0.41 \\
\hline 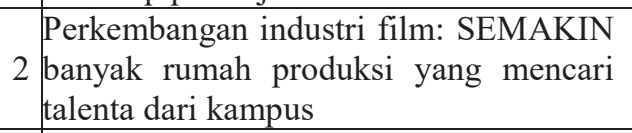 & 0.15 & 3.0 & 0.45 \\
\hline $3 \mid \begin{array}{llr}\text { UKM Movie } & \text { Production } & \text { Club yang } \\
\text { AKAN } & \text { SEMAKIN } & \text { banyak } \\
\text { membutuhkan talenta akting } & \end{array}$ & 0.15 & 3.3 & 0.51 \\
\hline $4 \mid \begin{array}{l}\text { Kemungkinan terjalinnya kemitraan } \\
\text { dengan LEBIH BANYAK koorporasi di } \\
\text { masa depan }\end{array}$ & 0.12 & 3.3 & 0.40 \\
\hline \multicolumn{4}{|l|}{ Ancaman } \\
\hline \begin{tabular}{l|l}
5 & $\begin{array}{l}\text { Kemunculan UKM lain yang DAPAT } \\
\text { menyedot mahasiswa }\end{array}$
\end{tabular} & 0.11 & 2.3 & 0.25 \\
\hline \begin{tabular}{l|l} 
& Penerapan intervensi penuh HRD \\
6 & terhadap perekrutan pada TA 2016/17 \\
\end{tabular} & 0.12 & 2.0 & 0.24 \\
\hline \begin{tabular}{l|l}
7 & $\begin{array}{l}\text { Rencana efesiensi anggaran sebanyak } \\
5 \% \text { pada TA 2016/17 }\end{array}$
\end{tabular} & 0.10 & 1.3 & 0.13 \\
\hline \begin{tabular}{l|l|} 
& Diangkatnya pimpinan baru yang \\
8 & kurang berpihak pada seni dan MPT \\
\end{tabular} & 0.12 & 3.3 & 0.41 \\
\hline \multicolumn{3}{|l|}{ Jumlah nilai tertimbang eksternal } & 2.81 \\
\hline \multicolumn{3}{|l|}{ Total Peluang } & 1.77 \\
\hline \multicolumn{3}{|l|}{ Total Ancaman } & 1.04 \\
\hline \multicolumn{3}{|l|}{ Interval } & 0.73 \\
\hline
\end{tabular}

\section{Analisa Perusahaan}

MPT saat ini tengah memasuki masa pendewasaannya. Setelah lebih kurang tujuh tahun berproses, kekacauan administrasi dan manajerial mulai bisa teratasi. Kehadiran Badan Pengurus Harian berdampak positif bagi pengelolaan MPT. Pertama, BPH membantu mengurusi hal-hal operasional yang mendetail sehingga instruktur sampai manajer tidak sesibuk dulu. Kedua, keterlibatan di BPH membuat para anggota memiliki komitmen yang lebih tinggi di MPT.

Dari sisi produk, proses latihan berjalan tidak serutin pada masa awal-awal berdiri. Namun, sudah membaik dibandingkan masa dua sampai tiga tahun yang lalu. Masih terlalu dini mengatakan ini sebuah kemajuan atau hanya letupan sesaat saja dan oleh sebab itu pemantauan terus menerus tetap perlu dilakukan. Dari kualitas, terjadi penurunan dibandingkan angkatan awal. Hal ini berusaha diatasi dengan berbagai workshop, namun kurangnya latihan memang disinyalir merupakan problem mendasar dari penurunan kualitas ini.

Jika secara organisasi menjadi lebih baik dan secara produk mengalami penurunan, maka secara keseimbangan keuangan MPT tetap tergolong sehat. Meskipun jumlahnya tidak banyak, 
namun kemitraan yang terbangun sejauh ini memberi kontribusi dana yang sangat membantu proses produksi.

Dari sisi pemasaran, MPT telah membangun sistem komunikasi dan marketing yang sangat baik. Saat ini, web, LINE, dan sosial media lainnya telah digunakan secara efektif untuk membangun jejaring dengan sesama anggota dan bahkan alumni. Selain itu, MPT juga terlibat dalam banyak project fakultas dan kampus sehingga lebih menunjukkan eksistensi mereka di tengah mahasiswa UPH.

Terakhir, dari sisi fasilitas dan perlengkapan, tetap menjadi masalah klise bahwa kampus tidak menyediakan fasilitas yang memadai untuk sebuah pertunjukan serius. Gedung pertunjukan yang kurang memadai, mic dan sound yang sudah ketinggalan zaman, dan hal-hal semacam itu masih dialami dari masa ke masa. Meski demikian, setidaknya MPT mendapat angin segar dari murahnya biaya sewa gedung pertunjukan di Jakarta sejak masa kepemimpinan Gubernur DKI, Basuki T. P.

Berdasarkan analisis di atas, dibuatlah sebuah Matriks Evaluasi Faktor Internal yang berisikan poin-poin kunci mengenai kekuatan dan kelemahan yang dimiliki MPT saat ini. Matriks ini menunjukkan bahwa kekuatan yang dimiliki saat ini adalah peningkatan jumlah, $\mathrm{BPH}$, kompetensi instruktur, materi pengajaran, komunikasi, dan kemudahan mengakses gedung pertunjukan berkualitas di luar kampus. Meski demikian, MPT perlu segera mengantisipasi kelemahannya di sektor disiplin dan teknik anggota, kelengkapan properti dan kelayakan gedung, kemampuan berkompetisi, serta terakhir penciptaan karya yang sanggup memenuhi ekspektasi religiusitas UPH. Sama seperti Matriks EFE, Matriks IFE telah diverifikasi dan dikerjakan oleh para keyperson yang menghasilkan matriks berikut:

\section{Kekuatan dan Kelemahan (Matriks IFE)}

\begin{tabular}{|l|l|l|l|l|}
\hline \multicolumn{2}{|c|}{ Faktor Internal Kunci } & Bobot & Peringkat & $\begin{array}{l}\text { Nilai } \\
\text { tertimbang }\end{array}$ \\
\hline \multicolumn{3}{|l|}{ Kekuatan } \\
\hline 1 & $\begin{array}{l}\text { Jumlah anggota yang terus } \\
\text { meningkat }\end{array}$ & 0.10 & 3.3 & 0.32 \\
\hline 2 & $\begin{array}{l}\text { Terbentuk organisasi BPH yang } \\
\text { berjalan dengan rapi }\end{array}$ & 0.12 & 4.0 & 0.48 \\
\hline 3 & $\begin{array}{l}\text { Instruktur yang berkompeten di } \\
\text { bidangnya }\end{array}$ & 0.08 & 3.7 & 0.29 \\
\hline 4 & $\begin{array}{l}\text { Materi pengajaran yang menarik } \\
\text { Kemampuan mengoptimalisasi } \\
\text { media komunikasi }\end{array}$ & 0.09 & 3.3 & 0.31 \\
\hline 6 & $\begin{array}{l}\text { Tarif sewa gedung pertunjukan di } \\
\text { Jakarta yang mulai terjangkau }\end{array}$ & 0.08 & 3.0 & 0.38 \\
\hline Kelemahan & $\begin{array}{l}\text { Lemahnya kemampuan teknik dan } \\
\text { disiplin anggota }\end{array}$ & 0.07 & 2.0 & 0.13 \\
\hline 8. & $\begin{array}{l}\text { Kelengkapan properti pertunjukan } \\
\text { (mic, clip-on, HT) yang belum } \\
\text { memadai }\end{array}$ & 0.09 & 2.3 & 0.21 \\
\hline 9. & $\begin{array}{l}\text { Gedung pertunjukan yang di } \\
\text { bawah standar }\end{array}$ & 0.08 & 3.0 & 0.24 \\
\hline 10. & $\begin{array}{l}\text { Daya saing mahasiswa di luar } \\
\text { UPH }\end{array}$ & 0.07 & 2.3 & 0.17 \\
\hline
\end{tabular}




\begin{tabular}{|l|l|l|l|l|}
\hline 11. & $\begin{array}{l}\text { Ketidaksesuaian gaya MPT } \\
\text { dengan selera pasar (mahasiswa) }\end{array}$ & 0.09 & 2.3 & 0.21 \\
\hline 12. & $\begin{array}{l}\text { Belum mampu mencapai } \\
\text { ekspektasi kadar konten religius } \\
\text { dari UPH. }\end{array}$ & 0.06 & 2.7 & 0.17 \\
\hline Jumlah nilai tertimbang internal & 3.15 \\
\hline Total Kekuatan & 2.03 \\
\hline Total Kelemahan & 1.12 \\
\hline Interval & 0.91 \\
\hline
\end{tabular}

\section{Tahap pencocokkan (Matching stage)}

Setelah melalui tahap masukan, data yang diperoleh dicocokkan dengan tiga formula: Matriks IE, Kuadran SWOT, dan terakhir Matriks SWOT

\section{Matriks IE}

Formulasi pertama menggunakan Matriks IE yang menggabungkan hasil penjumlahan antara IFE dan EFE. Berdasarkan hasil evaluasi yang dilakukan, total bobot skor IFE MPT adalah 3.15 dan EFE MPT adalah 2.81. Jika kemudian dimasukkan ke dalam matriks di bawah ini, maka koordinatnya berada pada sel IV (lihat gambar).

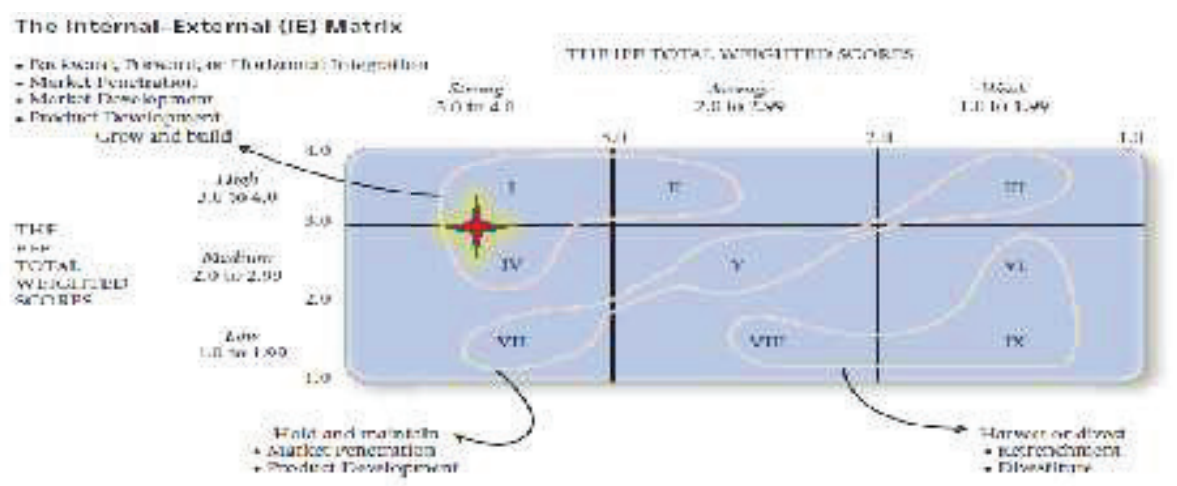

Gambar: Matriks IE pada David, 2011 adaptasi dari Allio and Pennington, eds. (1979)

Tanda bintang terletak pada sel IV yang mengindikasikan bahwa kondisi internal MPT berada dalam situasi kuat dan kondisi eksternalnya dalam posisi menengah agak ke tinggi. Ini menandakan bahwa kondisi MPT dapat dikatakan baik. Strategi yang harus diterapkan untuk kondisi saat ini adalah Growth and Build. Strategi yang tepat antara lain melakukan penetrasi pasar, pengembangan pasar, dan pengembangan produk serta integrasi ke belakang, integrasi ke depan, dan integrasi horizontal.

\section{Kuadran SWOT}

Kuadran SWOT masih memanfaatkan perhitungan IFE dan EFE sebelumnya. Akan tetapi, karena berusaha menemukan koordinat, maka setiap aspek di dalam IFE (KekuatanKelemahan) dan EFE (Peluang-Ancaman) akan dibandingkan dan dicari selisihnya.Dalam kasus ini, titik berada pada koordinat $(0.91,0.73)$ yang menandakan bahwa strategi yang tepat bagi MPT saat ini adalah Expansion, yaitu perluasan. Jika melihat koordinat tersebut, maka 
teknik paling tepat adalah memanfaatkan kekuatan untuk menyambut peluang (SO). Untuk lebih jelas mengenai SO, dapat melihat formulasi ketiga, yaitu Matriks SWOT.

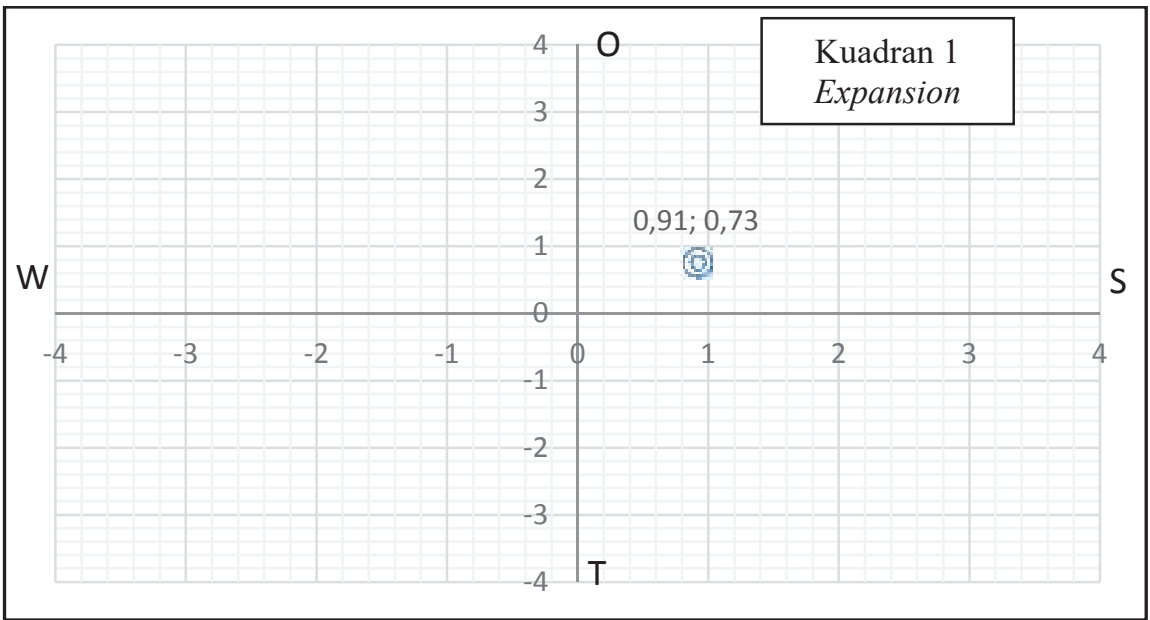

\section{Matriks SWOT}

\begin{tabular}{|c|c|c|}
\hline Eksternal & $\begin{array}{l}\text { Kekuatan / Strengths (S) } \\
\text { 1. Jumlah anggota yang } \\
\text { terus meningkat } \\
\text { 2. Terbentuk organisasi } \\
\text { BPH yang berjalan } \\
\text { dengan rapi } \\
\text { 3. Instruktur yang } \\
\text { berkompeten di } \\
\text { bidangnya } \\
\text { 4. Materi pengajaran } \\
\text { yang menarik } \\
\text { 5. Kemampuan } \\
\text { mengoptimalisasi } \\
\text { media komunikasi } \\
\text { 6. Tarif sewa gedung } \\
\text { pertunjukan di Jakarta } \\
\text { yang mulai terjangkau }\end{array}$ & $\begin{array}{l}\text { Kelemahan/ Weaknesses } \\
\text { (W) } \\
\text { 1. Lemahnya kemampuan } \\
\text { teknik dan disiplin } \\
\text { anggota } \\
\text { 2. Kelengkapan properti } \\
\text { pertunjukan (mic, clip- } \\
\text { on, HT) yang belum } \\
\text { memadai pertunjukan } \\
\text { 3. Gedung standar } \\
\text { yang di bawah sta ding mahasiswa di } \\
\text { 4. Daya saing } \\
\text { luar UPH } \\
\text { 5. Ketidaksesuaian gaya } \\
\text { MPT dengan selera pasar } \\
\text { (mahasiswa) } \\
\text { 6. Belum mampu mencapai } \\
\text { ekspektasi kadar konten } \\
\text { religius dari UPH. }\end{array}$ \\
\hline $\begin{array}{l}\text { Peluang/Opportunities } \\
\text { (O) } \\
\text { 1. Apresiasi pasar } \\
\text { yang bisa LEBIH } \\
\text { BAIK terhadap } \\
\text { pertunjukan teater } \\
\text { 2. Perkembangan } \\
\text { industri film: } \\
\text { SEMAKIN banyak } \\
\text { rumah produksi } \\
\text { yang mencari } \\
\text { talenta dari kampus } \\
\text { 3KM Movie } \\
\text { Production Club } \\
\text { yang AKAN } \\
\text { SEMAKIN banyak } \\
\text { membutuhkan } \\
\text { talenta akting }\end{array}$ & $\begin{array}{l}\text { Strategi SO } \\
\text { - Promosi secara gencar } \\
\text { di awal tahun ajaran } \\
\text { (S1-S5-O1) } \\
\text { - Undang House untuk } \\
\text { melakukan casting, } \\
\text { workshop, } \\
\text { penggalangan dana, dan } \\
\text { paket komplit lainnya } \\
\text { (S1-O2-O4) } \\
\text { - Kembali promosikan } \\
\text { kegiatan tersebut dalam } \\
\text { bentuk video pendek } \\
\text { (S5-O3) } \\
\text { - Membangun kemitraan } \\
\text { dengan banyak donatur } \\
\text { dan menyediakan } \\
\text { komunitasnya (S2-O4) }\end{array}$ & $\begin{array}{l}\text { Strategi WO } \\
\text { - Menggandeng mitra untuk } \\
\text { mensponsori berbagai } \\
\text { pelatihan bagi anggota } \\
\text { MPT (W1-O4) } \\
\text { - Melakukan pertunjukan di } \\
\text { luar lebih banyak dan } \\
\text { melibatkan pendanaan dari } \\
\text { luar UPH (W4-O4) }\end{array}$ \\
\hline
\end{tabular}




\begin{tabular}{|c|c|c|}
\hline $\begin{array}{l}\text { 4. Kemungkinan } \\
\text { terjalinnya } \\
\text { kemitraan dengan } \\
\text { LEBIH BANYAK } \\
\text { korporasi di masa } \\
\text { depan }\end{array}$ & $\begin{array}{l}\text { - Membuat banyak } \\
\text { pertunjukan kecil, } \\
\text { theatre-mob, dll yang } \\
\text { eye-catching di peak- } \\
\text { time makan siang (S3- } \\
\text { S4-O1) }\end{array}$ & \\
\hline $\begin{array}{l}\text { Ancaman / Threats }(\boldsymbol{T}) \\
\text { 1. Kemunculan UKM } \\
\text { lain yang DAPAT } \\
\text { menyedot } \\
\text { mahasiswa } \\
\text { 2. Penerapan } \\
\text { intervensi penuh } \\
\text { HRD terhadap } \\
\text { perekrutan pada TA } \\
\text { 2016/17 } \\
\text { 3. Rencana efesiensi } \\
\text { anggaran sebanyak } \\
\text { 5\% pada TA } \\
\text { 2016/17 } \\
\text { 4iangkatnya } \\
\text { pimpinan baru yang } \\
\text { kurang berpihak } \\
\text { pada seni dan MPT }\end{array}$ & $\begin{array}{l}\text { Strategi ST } \\
\text { - Mengkomunikasikan } \\
\text { keunggulan dan } \\
\text { diferensiasi MPT } \\
\text { dalam berbagai media } \\
\text { visual maupun audio } \\
\text { di awal semester (S5- } \\
\text { T1) } \\
\text { - Memanfaatkan relasi } \\
\text { pelatih untuk } \\
\text { diundang melakukan } \\
\text { berbagai workshop } \\
\text { (S2-S3-S4-T2) } \\
\text { Memangkas pos-pos } \\
\text { yang tidak produktif } \\
\text { dan memanfaatkan } \\
\text { berbagai momen } \\
\text { murah dengan } \\
\text { maksimal (S6-T3) }\end{array}$ & $\begin{array}{l}\text { Strategi TW } \\
\text { - Perketat disiplin latihan } \\
\text { dan fokus pada minat } \\
\text { tertentu saja per anggota } \\
\text { (W1-T1) } \\
\text { - Menyebar angket untuk } \\
\text { memahami segmentasi } \\
\text { pasar dan memutuskan } \\
\text { targeting ke depannya } \\
\text { (W5-T1) } \\
\text { - Bekerja sama dengan } \\
\text { banyak pembuat naskah } \\
\text { untuk menemukan ide } \\
\text { cerita yang religius namun } \\
\text { tetap modern. Jika cocok, } \\
\text { pembuat naskah bisa } \\
\text { direkrut (W6-T2) } \\
\text { - Menjalin komunikasi } \\
\text { dengan pemimpin baru } \\
\text { (W2-W3-T4) }\end{array}$ \\
\hline
\end{tabular}

Berdasarkan tiga formulasi di atas, maka diperoleh hasil sebagaimana dirangkum dalam tabel berikut:

\begin{tabular}{|c|c|c|}
\hline \multicolumn{3}{|c|}{ Tabel Formula dan Hasil } \\
\hline Matriks IE & Kuadran SWOT & Matriks SWOT \\
\hline $\begin{array}{l}\text { GROW AND } \\
\text { BUILD: } \\
\text { penetrasi pasar, } \\
\text { pengembangan pasar, } \\
\text { pengembangan produk, } \\
\text { integrasi ke belakang, } \\
\text { integrasi ke depan, dan } \\
\text { integrasi horizontal }\end{array}$ & EXPANSION & $\begin{array}{l}\text { SO (Strengths } \\
\text { Opportunity) } \\
\text { Promosi secara gencar } \\
\text { di awal tahun ajaran (S1-S5- } \\
\text { O1) Undang House untuk } \\
\text { casting, } \\
\text { melakukan penggalangan } \\
\text { workshop, komplit } \\
\text { dana, dan paket ko } \\
\text { lainnya (S1-O2-O4) } \\
\text { Kembali promosikan } \\
\text { kegiatan tersebut dalam } \\
\text { bentuk video pendek (S5-O3) } \\
\text { Membangun kemitraan } \\
\text { dengan banyak donatur dan } \\
\text { menyediakan komunitasnya } \\
\text { (S2-O4) Membuat banyak } \\
\text { Mertunjukan kecil, theatre- } \\
\text { mob, dll yang eye-catching di } \\
\text { peak-time makan siang (S3- } \\
\text { S4-O1) }\end{array}$ \\
\hline
\end{tabular}




\section{Tahap Keputusan (Decision Stage)}

Setelah tahap masukan dan pencocokan, tahap terakhir dalam Strategy-Formulation Analytical Framework adalah tahap keputusan. Dalam tahap ini, mengacu kepada tiga formulasi yang telah ditemukan, maka dibuatlah rekomendasi sebuah formulasi strategi agar MPT semakin menegaskan eksistensinya dan mencapai visi, misi, tujuan, serta sasaran mereka. Beberapa rekomendasi tersebut adalah:

\section{Memperluas Pasar, Menggali Lebih Dalam}

Mengacu pada hasil IE Matrix (Penetrasi Pasar) dan SWOT Quadrant (Expansion) maka strategi pertama yang perlu dilakukan MPT adalah memperluas pasarnya sambil mencengkram pasar yang ada dengan lebih kuat. Artinya, dalam jangka pendek ke depan MPT perlu menjaring segmen yang lebih luas untuk memaksimalkan kuantitas dan kualitas yang mungkin diperoleh.

\begin{tabular}{|l|l|}
\hline Tahun 1 & $\begin{array}{l}\text { - Gencar melakukan promosi di berbagai media, baik tentang aktivitas, acara, dan value yang } \\
\text { diusung oleh MPT. } \\
\text { - Membangun suatu brand image yang gaul, asik, tidak ketinggalan zaman, gila, seru, menarik, } \\
\text { dan hal-hal yang sangat anak muda. }\end{array}$ \\
\hline Tahun 2 & $\begin{array}{l}\text { - Merambah ke segmen baru: Setelah promosi gencar, perlu ada upaya untuk targeting segmen } \\
\text { atas. Tujuannya adalah untuk menambahkan brand image MPT sebagai sesuatu yang disukai } \\
\text { oleh kalangan atas. }\end{array}$ \\
& $\begin{array}{l}\text { Di sisi lain, terus memelihara kekeluargaan dan sama rata sama rasa antaranggota agar tidak } \\
\text { tercipta gap. }\end{array}$ \\
\hline Tahun 3 & $\begin{array}{l}\text { Merawat segmen baru menjaga segmen lama. Saatnya menjaga semua yang telah diraih dan } \\
\text { memastikan pencapaian telah maksimal. Tahap ini justru yang paling penting untuk } \\
\text { sustainability MPT ke depannya. }\end{array}$ \\
\hline
\end{tabular}

\section{Mengembangkan Produk Inovatif}

Sesuai hasil formulasi IE Matrix tentang pengembangan produk, maka penting bagi MPT untuk menonjolkan keunggulan dan diferensiasi mereka dari sisi produk. Seperti disebutkan di awal, produk meliputi program latihan, pementasan, pembangunan komunitas, pembentukan mental anggota, dan membangun kesadaran sosial anggotanya. Untuk itu, wujud kegiatan perlu dibuat semenarik mungkin agar menarik banyak peminat untuk bergabung.

\begin{tabular}{|l|l|}
\hline Tahun 1 & $\begin{array}{l}\text { - Mengadakan banyak workshop, casting, dan bincang-bincang dengan banyak tokoh terkenal } \\
\text { yang digabung dalam satu paket acara. Mengadakannya secara rutin. } \\
\text { - Membuat banyak pertunjukan yang unik dan tidak terpikirkan, ditampilkan di saat-saat ramai, } \\
\text { bertujuan untuk menggugah mahasiswa tentang sebuah isu yang sedang hangat. }\end{array}$ \\
\hline Tahun 2 & $\begin{array}{l}\text { - Meningkatkan skala acara di atas. } \\
\text { - Membuat lebih banyak pertunjukan yang meresponi masalah sosial, namun ringan, lucu, dan } \\
\text { menarik bagi mahasiswa }\end{array}$ \\
\hline Tahun 3 & $\begin{array}{l}\text { - Membuat tim kreatif yang terus menerus menggodok dan menelurkan ide-ide mereka sendiri, } \\
\text { berlatih menciptakannya menjadi karya-karya lingkungan yang dapat dipertunjukkan juga di } \\
\text { berbagai acara masyarakat sekitar }\end{array}$ \\
\hline
\end{tabular}




\section{Membangun Integrasi yang Kuat}

Hal yang tak kalah penting selama tiga tahun ke depan adalah membangun integrasi. Sebagaimana ditemukan dalam formulasi IE Matrix, penting bagi MPT untuk menjalin hubungan komunikasi dan kerjasama dengan setiap fakultas yang ada di UPH, terutama yang menyumbangkan porsi besar di keanggotaan MPT. Integrasi tersebut dapat berbentuk tawaran mengisi acara fakultas, HMJ, atau BEM dengan gratis atau dapat juga melibatkan mereka dalam kegiatan produksi karya.

Selain itu, integrasi juga bicara tentang bagaimana membangun kemitraan dengan sponsor. MPT perlu mempersiapkan BPH untuk selama tiga tahun belajar melahirkan dan memelihara hubungan dengan berbagai donatur dan sponsor.

\section{Selalu Menghadirkan Karya yang Menarik}

Terakhir, tetapi tidak kalah penting. MPT perlu hadir menjadi terang, memberi dampak lewat karyanya. Di lingkungan UPH yang sangat terstruktur dan steril, MPT perlu melakukan 'kekacauan' dalam batasan tertentu untuk menawarkan keriangan seni yang tidak kaku. Ini akan menjadi pembeda yang sulit disamai oleh UKM lain, setidaknya tiga hingga lima tahun ke depan.

\section{Kesimpulan}

Manna Proxia Theatre (MPT) adalah sebuah Unit Kegiatan Mahasiswa (UKM) di Universitas Pelita Harapan yang sejatinya berpusat pada upaya untuk menyediakan wadah belajar/pendidikan bagi para anggotanya. Di tengah upaya sinergi antara BPH yang baru terbentuk dan instruktur yang ada, MPT saat ini berhadapan dengan kondisi lingkungan yang baru yang memberikan peluang dan ancaman bagi perkembangan MPT kedepannya. Agar terus bertahan, MPT perlu mengenali kekuatan dan kelemahannya kemudian mengelolanya sehingga dapat menangkap peluang dan sebisa mungkin meminimalisir dampak ancaman yang akan terjadi.

Untuk itulah, dilakukan analisa SWOT terhadap MPT yang menghasilkan beberapa strategi agar MPT dapat terus kompetitif sebagai sebuah UKM di UPH. Dengan melibatkan para pengambil keputusan (key person) di MPT, disusunlah sebuah analisa kualitatif tentang kondisi internal (kekuatan dan kelemahan) serta eksternal (peluang dan ancaman) MPT saat ini. Selanjutnya, data kualitatif dicocokkan ke dalam Matriks IE dan ditemukan bahwa MPT berada dalam area Grow and Build. Pencocokan lain dengan menggunakan Kuadran SWOT menemukan bahwa MPT berada dalam Kuadran I, yaitu Expansion. Terakhir, melalui Matriks SWOT ditemukan bahwa MPT termasuk perlu melakukan strategi SO yang memanfaatkan kekuatan untuk meraih peluang yang tersedia. Pada akhirnya, dirumuskanlah beberapa strategi jangka pendek meliputi: memperluas pasar, terus mengembangkan produk-produk baru, membangun integrasi yang kuat dengan berbagai pihak di dalam maupun luar kampus, dan terus menghadirkan karya-karya yang unik dan menarik perhatian masyarakat kampus. 


\section{Kepustakaan}

Allio, R. J., dan Pennington, M. W., eds. Dalam David, F. R. (2011). Strategic management: concepts and cases. New Jersey: Prentice Hall.

David, F. R. (2011). Strategic management: concepts and cases. New Jersey: Prentice Hall.

Gluck, Kaufman, dan Walleck (1982) dalam Wells, D. L. (1996). Strategic Management for Senior Leaders: A Handbook for Implementation. Department of the Navy, Total Quality Leadership Office.

Haryanto, S. (2014). Kajian Wisata Seni Budaya Batik Berwawasan Lingkungan di Desa Jamur, Kecamatan Bayat, Kabupaten Klaten, Provinsi Jawa Tengah (Thesis). Yogyakarta: Pascasarjana ISI Yogyakarta

Indriyanti, P. (2013). Strategi Tata Kelola Andong Wisata Sebagai Salah Satu Daya Tarik Wisata Kota Yogyakarta (Thesis). Yogyakarta: Pascasarjana ISI Yogyakarta

Fahmi, 2013 dalam Nisak, Z. (2013). Analisis SWOT untuk menentukan strategi kompetitif. Jurnal Eksbis. 9 (2). Didapat dari : http://journal.unisla.ac.id/pdf/12922013/4.pdf

Park, J. (2015). Catatan perkuliahan Prinsip-prinsip Seni Pertunjukan Jurusan Tata-Kelola Seni Konsentrasi Seni Pertunjukan. Yogyakarta: Institut Seni Indonesia Yogyakarta.

Rangkuti F. (2004). Analisis SWOT Teknik Membedah Kasus Bisnis. Jakarta: PT. Gramedia.

Singh, 2010 dalam Ommani, Ahmad Reza. (2011). Strengths, weaknesses, opportunities and threats (SWOT) analysis for farming system businesses management: Case of wheat farmers of Shadervan District, Shoushtar Township, Iran. African Journal of Business Management 5(22), pp. 9448-9454. ISSN 1993-8233.

Wells, D. L. (1996). Strategic Management for Senior Leaders: A Handbook for Implementation. Department of the Navy, Total Quality Leadership Office.

Whalley, A. (2010). Strategic Marketing. Andrew Whalley and Ventus Publishing APS. ISBN 978-87-7681-643-8

\section{Sumber lain :}

ART Division Universitas Pelita Harapan website (art.uph.edu) 